\title{
Development of a questionnaire to assess patient satisfaction with allergen-specific immunotherapy in adults: item generation, item reduction, and preliminary validation
}

\author{
This article was published in the following Dove Press journal: \\ Patient Preference and Adherence \\ 24 May 2011 \\ Number of times this article has been viewed
}

Jose Luis Justícia'

Eva Baró ${ }^{2}$

Victoria Cardona ${ }^{3}$

Pedro Guardia ${ }^{4}$

Pedro Ojeda ${ }^{5}$

José Maria Olaguíbel ${ }^{6}$

José Maria Vega ${ }^{7}$

Carmen Vidal ${ }^{8}$

'Medical Department, Stallergenes Ibérica, Barcelona, Spain; ${ }^{2}$ Health

Outcomes Research Department, 3D

Health Research, Barcelona, Spain;

${ }^{3}$ Hospital Vall d'Hebron, Barcelona,

Spain; ${ }^{4}$ Hospital Virgen Macarena,

Sevilla, Spain; ${ }^{5}$ Clínica de Asma y

Alergia Dres. Ojeda, Madrid, Spain;

${ }^{6}$ Complejo Hospitalario de Navarra,

Pamplona, Spain; ${ }^{7}$ Hospital Regional

Universitario Carlos Haya Málaga,

Spain; ${ }^{8}$ Complejo Hospitalario

Universitario de Santiago, Santiago

de Compostela, Spain
Correspondence: Jose Luis Justícia Stallergenes Iberica, C/Ramon Turró 91, Baixos, Barcelona 08005, Spain

$\mathrm{Tel}+34932219611$

Fax +34932 259829

Email jjusticiar@stallergenes.es
Background: Allergen-specific immunotherapy (SIT) is a treatment capable of modifying the natural course of allergy, so ensuring good adherence to SIT is fundamental. Up until now there has not existed an instrument specifically developed to measure patient satisfaction with SIT, although its assessment could help us to comprehend better and improve treatment adherence and effectiveness. The aim of this study was to develop an instrument to measure adult patient satisfaction with SIT.

Methods: Items were generated from a literature review, focus groups with allergic adult patients undergoing SIT, and a meeting with experts. Potential items were administered to allergic patients undergoing SIT in an observational, cross-sectional, multicenter study. Item reduction was based on quantitative and qualitative criteria. A preliminary assessment of feasibility, reliability, and validity of the retained items was performed.

Results: An initial pool of 70 items was administered to 257 patients undergoing SIT. Fifty-four items were eliminated resulting in a provisional instrument with 16 items. Factor analysis yielded four factors that were identified as perceived efficacy, activities and environment, cost-benefit balance, and overall satisfaction, explaining $74.8 \%$ of variance. Ceiling and floor effects were negligible for overall score. Overall score was associated with the type and intensity of symptoms.

Conclusion: This is the first attempt to develop a satisfaction with SIT measure from the perspective of the allergic patient, and evidence has been found in favor of its reliability and validity.

Keywords: allergy, allergen-specific immunotherapy, questionnaire, scale, assessment, satisfaction

\section{Introduction}

Treatment satisfaction is defined as the individual's rating of important attributes of the process and outcomes of his/her treatment experience. ${ }^{1}$ While health status instruments measure the results of treatment, eg, in perceived biological, symptomatic or welfare (quality of life) terms, treatment satisfaction scales assess the level of satisfaction with the said results, ${ }^{2}$ so that presumably, assessment of patient satisfaction with treatment could contribute to understanding and improving treatment adherence and thereby improve results with regard to health. Some years have passed since the first conceptual approaches, ${ }^{1}$ up to subsequent revisions, ${ }^{2,3}$ and there seems to be a certain consensus, in that patient satisfaction with treatment is influenced by patient 
characteristics (eg, their preferences and expectations), the characteristics of the health problem being treated (eg, symptom severity), the characteristics of pertinent health care system and, obviously, the characteristics of the treatment in question (ie, effectiveness, discomfort, cost, adverse effects, and associated limitations of the medication). The assessment of patient satisfaction with treatment should contemplate these aspects, and should be carried out with duly developed instruments that take into account the patient's perspective during its development. ${ }^{1-3}$ Currently, there already exist multidimensional scales that assess treatment satisfaction (referring solely to the medication employed or including other aspects relative to the treatment) regarding different illnesses ${ }^{4-8}$ or symptoms. ${ }^{9-12}$ There are also more generic instruments, eg, that assess the chronic patient's treatment satisfaction in general, as is shown in the case of the Treatment Satisfaction Questionnaire for Medication that includes dimensions common to chronic treatments ${ }^{13,14}$ or other scales. ${ }^{15}$ In this way, the same thing probably happens with regard to patient satisfaction as it does in health-related quality of life assessment, where specific and generic instruments are complementary because they contribute different kinds of information and achieve different objectives.

Allergy prevalence is growing worldwide, ${ }^{16}$ and its therapeutic management often employs on-demand symptomatic treatment to minimize the symptoms as a complement to allergen-specific immunotherapy, a treatment that is capable of modifying the natural course of the illness, ${ }^{17,18}$ so ensuring good adherence to this treatment is fundamental. However, as happens with chronic treatment, patients receiving allergen-specific immunotherapy can be noncompliant, mainly due to inconvenience, a feeling of inefficacy, cost, and side effects. ${ }^{19,20}$ Theoretically, this lack of adherence minimizes the effectiveness of the treatment, has repercussions on patient satisfaction, and reinforces noncompliance, as was found with other chronic illnesses, such as diabetes ${ }^{21}$ and human immunodeficiency virus infection. ${ }^{22}$ Given that treatment satisfaction has been associated with the willingness to continue the said treatment, ${ }^{23}$ one could hypothesize that the more the patient is satisfied with his/her specific immunotherapy, the more likely he/she will be to adhere to and comply with the treatment over the treatment period.

\section{Materials and methods}

The three main phases of the project consisted of item generation, item reduction with data collected in a first field-work study, and an exhaustive assessment of the psychometric properties of the questionnaire's final version, with data collected in subsequent field work. This paper reports the main results of the first two steps of the overall project (Figure 1).

\section{Item generation}

The content of the questionnaire was developed from November 2008 to March 2009 from a literature review, focus groups and expert opinions from allergologists and experts in the development of patient-reported outcomes (PRO) measures. The literature review included a search of the Medline database (1966-2008) using search terms, including "patient satisfaction", "treatment satisfaction", "questionnaire", "scale preferences", "respiratory", and "allergy". The articles located were searched manually for further relevant articles. The review of instruments was mainly intended to identify the usual questionnaire content at domain level.

The initial consultation with experts (allergologists and experts in the development of PRO measures) took place at a meeting in Madrid. We used a structured brainstorming technique to establish the experts' views on the potential content, usefulness, and formal characteristics of the new questionnaire that would make it practical for use in standard clinical practice.

Three focus groups were formed ${ }^{24}$ in the allergy departments at three different health centers in Madrid, Pamplona, and Seville where three of the study investigators are located (PO, JMO, and PG, respectively). Each center selected 7-9 candidate patients to participate in the sessions on the basis of the following requirements: they had to be patients with allergy over 18 years of age and been undergoing specific immunotherapy treatment for at least four months. Each group was to be well balanced as to gender, sociocultural status, (high, middle, or low), the allergen to which they were allergic (pollens and/or dust mites), the kind of set pattern (preseasonal or perennial), and the method of specific immunotherapy administration (subcutaneous or sublingual). All participants gave their formal consent to participate.

The meetings were led by a moderator assisted by a script specifically developed for this purpose. The script included questions about aspects that the experts had considered as potentially relevant in the initial consultation, as well as questions to identify other aspects not identified by the experts but which were considered relevant by the participating patients (ie, Which aspects do you feel are important for you to be satisfied with an allergy vaccine? What aspect do you consider to be most important regarding your allergy vaccine? What don't you like about your allergy vaccine?). 


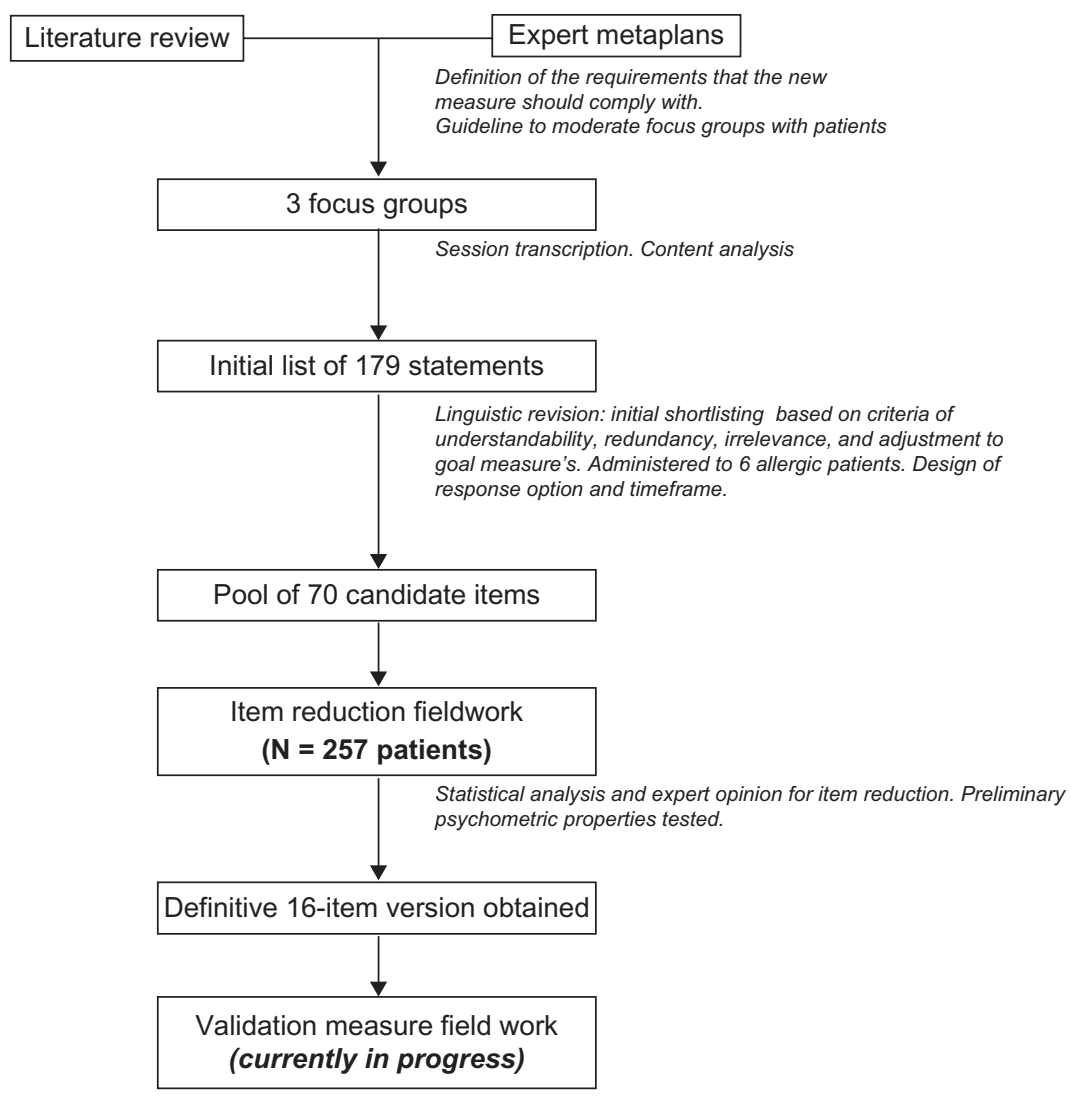

Figure I Overview of study procedures.

A content analysis of transcripts from the focus groups was performed by two of the study team members, and the results were used to develop an initial pool of items for inclusion in the questionnaire. This pool was administered to six allergic patients other than those who participated in the focus groups, so that redundant items as well as those ambiguous or lacking in face validity were omitted. The wording and phrasing used by focus group members was retained wherever possible. An agreement was reached with clinical experts on using "two months" as a suitable time frame for items in the pool. All the aforementioned procedures were carried out in Spanish.

\section{Item reduction}

\section{Study design and participants}

The pool of items considered for inclusion in the final version of the questionnaire was administered to allergic patients undergoing allergen-specific immunotherapy in an observational, cross-sectional, multicenter study performed between June 2009 and September 2009 in the allergy units of 20 Spanish hospitals or health care centers. Each centre consecutively included patients 18 years old or over, with a diagnosis of respiratory allergy, who had received or were receiving immunotherapy with aeroallergens (pollens or mites) by the subcutaneous or sublingual route, for at least six months constantly and/or for a minimum of two specific immunotherapy preseasonal cycles. All patients provided their informed consent to participate in the study. The study was conducted according to the Declaration of Helsinki and was approved by the Ethics Committee of the Hospital Universitari Vall d'Hebron in Barcelona.

Data were collected about the patient's gender, age, and level of education. The clinical characteristics recorded included time since diagnosis, allergen sensitization, comorbidities, type and intensity of main symptoms, type and regimen of allergen-specific immunotherapy, and symptomatic treatment. All patients included in this phase of the study were asked how frequently they experienced the situation presented in each of the items and whether the item was important to them, each on five-point scales.

\section{Statistical analysis}

Item reduction involved a series of steps: missing responses were analyzed to exclude those items with a relevant percentage of responses missing; the response distribution was analyzed and items with endorsement rates (percentage of respondents that checked the same response category) of 
over $70 \%$ were excluded; ${ }^{25}$ and the frequency and importance scores were analyzed for each item. In this part of the item reduction process, the product of the frequency and importance scores (the "impact" score) was obtained for each item and then ranked and selected according to this product; redundancy of items was also taken into consideration throughout the item reduction process; the decision about which items to retain when redundancy or high correlations occurred (Pearson $>0.85$ ) was based on the relative clinical relevance of the items; and the relationships between all items and their posited scales were analyzed by the calculation of corrected item-scale correlations and analysis of the impact on Cronbach's alpha values.

Using the data collected in the item reduction study, and with the aim of initially exploring the questionnaire performance, the internal consistency, construct validity (known-groups), and content validity ${ }^{26}$ (factor analysis by means of principal component analysis, Varimax rotation) were assessed for the retained items. Following the recommendations set out in the literature, ${ }^{25,27}$ the overall score for the final version of the questionnaire was obtained by adding the scores from all the items, and the score for each dimension was obtained by adding the scores for the items in that dimension. For individual patients included in the study, overall scores were not calculated when the questionnaire had any item missing. The distribution of the overall and dimension scores was described by calculating score range and floor/ceiling effects (the proportion of patients with the worst and the best possible scores, respectively). Reliability for the overall score and dimension score was assessed in terms of internal consistency using Cronbach's alpha (values of 0.70 or over are considered adequate). ${ }^{25}$ A preliminary assessment of the prevalidated questionnaire was tested by determining whether the instrument was able to discriminate between patient groups likely to differ in patient-satisfaction with specific immunotherapy. It includes type and intensity of allergic rhinitis according to the Allergic Rhinitis and its Impact on Asthma guidelines, ${ }^{16}$ and symptomatology (presence and intensity of rhinorrhea and sneezing) as the tested independent variables.

\section{Results}

\section{Item generation}

The literature review identified 17 citations that were considered potentially relevant to the study, which identified several instruments or surveys of interest, mainly focused on preferences and satisfaction with inhalation devices in asthma, ${ }^{28,29}$ satisfaction with asthma health care services, ${ }^{30,31}$ satisfaction with corticosteroid treatment for asthma, ${ }^{32}$ and allergies treated with sublingual allergen-specific immunotherapy that included some questions about satisfaction with treatment. ${ }^{33}$

Asked to consider the three main issues addressed in the brainstorming session, the experts mentioned the following as the most relevant questions to be attended to for the development of the questionnaire: treatment efficacy, cost, daily inconveniences derived from the logistics of administering the treatment, adverse reactions, and the way of administering the treatment. They also thought that the questionnaire should be useful in clinical practice, especially to improve treatment compliance (eg, helping to identify patients who risk abandoning the treatment), to provide relevant information on decisions to be taken after beginning allergen-specific immunotherapy, as well as to be brief, easy to score and use, and preferably self-administered.

A pool of 70 items was generated with the information obtained from the 24 participants in the focus group, together with input from the literature review and the brainstorming with experts.

\section{Item reduction and preliminary validation}

The pool of items was administered to 257 allergic patients, mostly young adults, well balanced in gender and with high educational levels. The study sample had been diagnosed as having had a respiratory allergy for more than seven years, mainly due to pollen. At the time of inclusion, the study sample showed a considerable level of symptoms. All the patients were undergoing allergen-specific immunotherapy treatment, mainly by the subcutaneous route $(63.4 \%$, see Table 1$)$.

Fifty-four of the initial 70 items included in the item reduction phase were eliminated. The reasons for their elimination and the number of items eliminated for each reason are shown in Figure 2. With respect to the quantitative criteria applied for the process of item reduction, three of them, ie, poor response distribution, impact score and ranking (see summary in Table 2), and internal consistency parameters (item-total correlation and contribution to Cronbach's alpha) were found to be the most efficient, and responsible for eliminating 47 of the initial items. Six items were eliminated due to qualitative criteria, leaving a prevalidated version containing 16 items, the length of which would presumably be more apt for use in clinical practice. The decision regarding the elimination of each of the six items was widely discussed and taken by general consent by the group of investigators based on the face validity of the item, its redundancy, and the length or complexity of wording. 
Table I Demographic and disease characteristics of patients involved in quantitative item reduction $(n=257)$

\begin{tabular}{|c|c|}
\hline Gender, women, n (\%) & $133(5 \mid .8)$ \\
\hline \multirow[t]{2}{*}{ Age, years, mean (SD) [min, max] } & $33.2(10.7)$ \\
\hline & {$[18,7]$} \\
\hline \multicolumn{2}{|l|}{ Educational level, n (\%) } \\
\hline No formal education & $9(3.5)$ \\
\hline Primary education & $48(18.7)$ \\
\hline Secondary education & $103(40.1)$ \\
\hline University or similar & $94(36.6)$ \\
\hline Missing data & $3(1.1)$ \\
\hline Time since diagnosis, years, mean (SD) & $7.7(7.4)$ \\
\hline \multicolumn{2}{|l|}{ Allergen, n (\%) } \\
\hline Mite & $72(28.0)$ \\
\hline Pollen & $162(63.0)$ \\
\hline Both & $20(7.9)$ \\
\hline Missing data & $3(1.1)$ \\
\hline \multicolumn{2}{|l|}{ Comorbidities, n (\%) ${ }^{a}$} \\
\hline Asthma & $138(53.7)$ \\
\hline Conjunctivitis & $190(73.9)$ \\
\hline Other comorbidities & II (4.3) \\
\hline \multicolumn{2}{|l|}{ Type of asthma, $n(\%)^{b}$} \\
\hline Mild intermittent & $82(59.4)$ \\
\hline Mild persistent & $26(18.8)$ \\
\hline Moderate persistent & $24(17.5)$ \\
\hline Severe persistent & $2(1.4)$ \\
\hline Missing data & $4(2.9)$ \\
\hline \multicolumn{2}{|l|}{ Type of allergic rhinitis, n (\%) } \\
\hline Persistent & $99(38.5)$ \\
\hline Intermittent & $140(54.5)$ \\
\hline Missing data & $18(7.0)$ \\
\hline \multicolumn{2}{|l|}{ Severity of allergic rhinitis, $\mathbf{n}(\%)^{c}$} \\
\hline Mild & $83(32.3)$ \\
\hline Moderate & $122(47.5)$ \\
\hline Severe & $49(19.1)$ \\
\hline Missing data & $3(1.1)$ \\
\hline \multicolumn{2}{|c|}{ Type of allergen-specific immunotherapy, $n(\%)^{d}$} \\
\hline Sublingual & $93(36.2)$ \\
\hline Subcutaneous & $163(63.4)$ \\
\hline Both & $\mathrm{I}(0.4)$ \\
\hline \multicolumn{2}{|c|}{ Allergen-specific immunotherapy regimen, $n$ (\%) } \\
\hline Perennial & $202(78.6)$ \\
\hline Preseasonal & $44(17.1)$ \\
\hline Missing data & II (4.3) \\
\hline \multicolumn{2}{|l|}{ Symptomatic treatment, $n(\%)^{d}$} \\
\hline Corticosteroids & $26(10,1)$ \\
\hline Antihistamines & $61(23.7)$ \\
\hline Both & $128(49.8)$ \\
\hline Others & $53(20.6)$ \\
\hline
\end{tabular}

Notes: ${ }^{\text {PPatient }}$ could respond to more than one option; ' $\mathrm{A} A c c o r d i n g$ to the Global Initiative for Asthma classification; ; cAccording to Valero et al,;2 dAt inclusion. Abbreviations: SD, standard deviation; min, minimum; max, maximum.

In the factorial analysis done on the 16 retained items (Table 3), a four-factor solution was found that explained $74.8 \%$ of variance, with item-loading values ranging from 0.441 to 0.858 . The assignment to the final dimensions of those items that contributed to two different factors was performed by clinical criteria, so that the prevalidated questionnaire consisted of 16 items distributed in four dimensions, ie, perceived efficacy (four items), activities and environment (six items), cost-benefit balance (three items), and overall satisfaction (three items).

Table 4 shows the score distributions, floor/ceiling effects, and internal consistency for the prevalidated questionnaire. In total, $33.5 \%$ of the sample had at least one item missing of the 16 retained. Ceiling and floor effects were negligible $(<5 \%)$ in all dimensions and for the overall score, except for the ceiling effect of cost-benefit balance and overall satisfaction dimensions, for which almost $23 \%$ and $16 \%$ of patients obtained the best possible scores. Cronbach's alpha values were more than 0.70 for the overall score $(0.94)$ and for all dimensions (0.79-0.89).

Table 5 shows the results of testing the validity of the prevalidated questionnaire in the known groups. Patients with intermittent allergic rhinitis, mild allergic rhinitis (and specifically those with no troublesome symptoms according to Allergic Rhinitis and its Impact on Asthma classification) and those without sneezing symptoms, reported statistically significant $(P=0.051-0.039)$ better (higher) global scores than did patients with persistent allergic rhinitis, those with moderate/ severe intensity of allergic rhinitis, those reporting troublesome symptoms of allergic rhinitis and asthma, and those reporting sneezing symptoms. Statistically significant associations were not found between the questionnaire scores with regard to age, gender and type of allergen-specific immunotherapy (sublingual versus subcutaneous, data not shown).

\section{Discussion}

According to some authors, working within the patient satisfaction environment, there are several reasons why we should assess satisfaction with medication. On the one hand, although there are few existing developed studies, the relation between satisfaction with medication and medication compliance should be considered. On the other hand, knowing the patient's satisfaction with respect to a certain medication could lead to the improvement of products, ${ }^{3}$ that is to say, in the adaptation of the same to the requirements and expectations of the patient in question. Furthermore, assessment of satisfaction with medication would be particularly recommendable, for instance, in comparing similarly effective kinds of medications with different routes of administration, different profiles regarding side effects, or when the treatment plays a principal role in a certain therapeutic approach. ${ }^{3}$ All this reasoning fits in perfectly with the case of the allergic patient undergoing specific immunotherapy, where the 


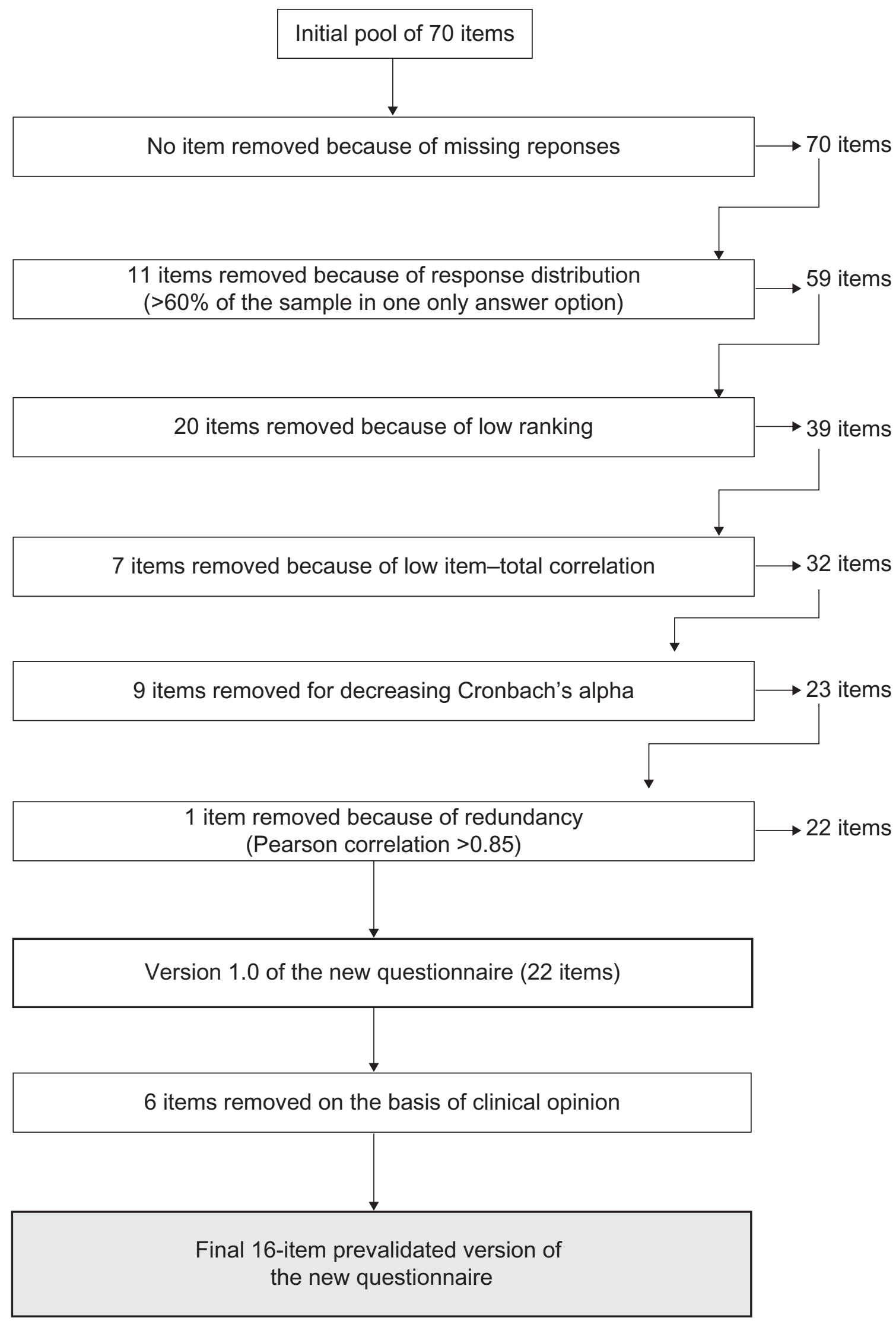

Figure $\mathbf{2}$ Items eliminated at different stages of the item reduction process. 
Table 2 Highest scoring items of the original 70 items $(n=254)$

\begin{tabular}{|c|c|c|c|}
\hline & $\begin{array}{l}\text { Mean (SD) } \\
\text { frequency }\end{array}$ & $\begin{array}{l}\text { Mean (SD) } \\
\text { importance }\end{array}$ & $\begin{array}{l}\text { Mean (SD) } \\
\text { impact score }\end{array}$ \\
\hline The vaccine is compatible with my life style & $1.6(0.9)$ & $1.7(0.9)$ & $2.9(2.3)$ \\
\hline My vaccine is easy to administer & $\mathrm{I} .7(\mathrm{I})$ & $\mathrm{I} .6(0.8)$ & $3(2.7)$ \\
\hline Generally speaking, I am satisfied with my allergy vaccine ${ }^{\mathrm{b}}$ & I.8 (I.I) & $\mathrm{I} .5(0.7)$ & $3(2.8)$ \\
\hline My vaccine works ${ }^{b}$ & $2.1(1)$ & $\mathrm{I} .5(0.7)$ & $3.2(2.5)$ \\
\hline Since being vaccinated I have felt much better & $2(1)$ & $1.5(0.7)$ & $3.3(2.7)$ \\
\hline Since being vaccinated for the allergy I present fewer symptoms ${ }^{b}$ & $2 . I(I)$ & $\mathrm{I} .5(0.7)$ & $3.5(2.4)$ \\
\hline I have fewer allergy crises, thanks to the vaccine & $2.1(1.1)$ & $1.5(0.7)$ & $3.5(3.1)$ \\
\hline In general, I would recommend the vaccine treatment ${ }^{b}$ & $\mathrm{I} .7(\mathrm{I})$ & $1.9(0.9)$ & $3.6(3.4)$ \\
\hline The medical treatment I receive helps me with the vaccine treatment & $1.8(0.9)$ & $1.8(0.9)$ & $3.8(4)$ \\
\hline I have felt better since receiving the vaccine & $2.1(I)$ & $1.7(0.8)$ & $3.8(3.1)$ \\
\hline My quality of life has improved since receiving the vaccine ${ }^{b}$ & $2.2(1.1)$ & $1.6(0.7)$ & $4(3.6)$ \\
\hline My vaccine gives me independence & $2(1.2)$ & $1.8(0.9)$ & $4.1(4.2)$ \\
\hline $\begin{array}{l}\text { The information I received at the start of the vaccine treatment has } \\
\text { helped me to understand how it works }\end{array}$ & $1.9(1.1)$ & $19(0.9)$ & $4.2(3.9)$ \\
\hline $\begin{array}{l}\text { The good performance of the vaccine compensates for having } \\
\text { to take it daily }\end{array}$ & $2.1(1.2)$ & $1.8(1)$ & $4.3(4.1)$ \\
\hline $\begin{array}{l}\text { The good performance of the vaccine compensates for any } \\
\text { inconveniences it could cause } \mathrm{me}^{\mathrm{b}}\end{array}$ & $2.1(1.1)$ & $1.9(0.9)$ & $4.3(3.7)$ \\
\hline $\begin{array}{l}\text { The good performance of the vaccine compensates for the } \\
\text { financial challenge it causes } \mathrm{me}^{\mathrm{b}}\end{array}$ & $2.2(1.2)$ & $1.8(0.9)$ & $4.4(3.7)$ \\
\hline $\begin{array}{l}\text { The good performance of the vaccine compensates for all the } \\
\text { things I have to do to obtain it (appointments, prescriptions, leave) }\end{array}$ & $2.2(1.2)$ & $1.9(1.5)$ & $4.6(3.9)$ \\
\hline My vaccine doesn't produce side effects & $2.4(1.6)$ & $1.7(1)$ & $4.7(5.6)$ \\
\hline Thanks to the vaccine I can work or study better ${ }^{\mathrm{b}}$ & $2.5(1.2)$ & $1.9(1)$ & $5.4(5.1)$ \\
\hline $\begin{array}{l}\text { Thanks to the vaccine I only need an inhaler or take pills at certain } \\
\text { or isolated times }\end{array}$ & $2.5(1.4)$ & $1.9(1)$ & $5.4(5.3)$ \\
\hline $\begin{array}{l}\text { If I had known about the vaccine before I would have started } \\
\text { with it earlier }\end{array}$ & $2.3(I-3)$ & $1.9(1)$ & $5.4(5.5)$ \\
\hline Since receiving the vaccine I enjoy outdoor activities more ${ }^{b}$ & $2.5(1.2)$ & $2(1)$ & $5.5(4.9)$ \\
\hline My vaccine helps me feel better physically & $2.5(1.1)$ & $1.9(0.9)$ & $5.6(4.8)$ \\
\hline Getting vaccinated is easy and quite quick & $2.5(1.3)$ & $2.1(1)$ & $5.7(4.3)$ \\
\hline My vaccine works faster than I had expected & $2.8(1.2)$ & $1.9(0.9)$ & $5.8(4.4)$ \\
\hline $\begin{array}{l}\text { Since being vaccinated I don't continually interrupt my activities } \\
\text { due to allergy symptoms }\end{array}$ & $2.6(1.2)$ & $2(0.9)$ & $5.8(4.9)$ \\
\hline My vaccine helps me to carry out my daily activities ${ }^{b}$ & $2.6(1.3)$ & $2(1.1)$ & $6.2(6.1)$ \\
\hline Since being vaccinated I can go anywhere with my family or friends ${ }^{\mathrm{b}}$ & $2.5(1.4)$ & $2.1(1.2)$ & $6.2(6)$ \\
\hline Getting vaccinated results in physical problems & $2.7(1.4)$ & $2.1(1)$ & $6.2(5)$ \\
\hline Thanks to the treatment I understand my illness better & $2.4(1.3)$ & $2.2(1.1)$ & $6.4(6.2)$ \\
\hline $\begin{array}{l}\text { Since being vaccinated the physical problems related with the } \\
\text { allergy (sneezing, runny nose, headaches, itching) don't bother me }\end{array}$ & $3(1.2)$ & $2(1)$ & $6.5(5)$ \\
\hline $\begin{array}{l}\text { Thanks to the vaccine, I am less dependent on always having } \\
\text { to carry other medication (pills, inhalers, etc) }\end{array}$ & $2.9(1.4)$ & $2.1(1.1)$ & $6.8(6)$ \\
\hline Taking the vaccine daily does not involve any extra effort & $3(1.3)$ & $2.3(1.2)$ & $6.8(4.8)$ \\
\hline $\begin{array}{l}\text { Since taking the vaccine I do not find myself in compromising } \\
\text { or uncomfortable situations caused by my allergy symptoms }\end{array}$ & $2.8(1.2)$ & $2.3(1.1)$ & $6.9(5.5)$ \\
\hline $\begin{array}{l}\text { I am happy with the vaccine and having to travel and organize } \\
\text { myself to get vaccinated does not present a problem }\end{array}$ & $2.9(1.2)$ & $2.2(1)$ & $7(4.9)$ \\
\hline $\begin{array}{l}\text { Thanks to the vaccine I no longer have to leave certain places } \\
\text { because of my allergy symptoms }\end{array}$ & $2.9(1.2)$ & $2.2(I . I)$ & $7.4(5.9)$ \\
\hline $\begin{array}{l}\text { Since being vaccinated I don't have to avoid things that I like but } \\
\text { which caused my allergyc }\end{array}$ & $3(1.2)$ & $2.3(I . I)$ & $7.6(6.2)$ \\
\hline $\begin{array}{l}\text { Since being vaccinated I am no longer concerned about being } \\
\text { in contact with the cause of my allergy }\end{array}$ & $3.1(1.2)$ & $2.3(2.8)$ & 7.9 (II.9) \\
\hline
\end{tabular}

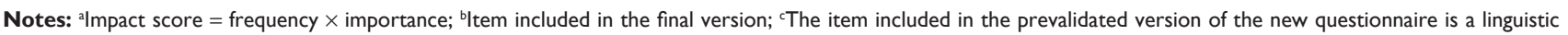
reform of this item; the table includes 39 items after excluding the II items eliminated because of response distribution and the 20 worst score ranking items; the original tool has been developed entirely in Spanish; this is not an official version in English, but a translation for informational purposes only. 
Table 3 Factor analysis for the 16 retained items of the new questionnaire $(n=254)^{a}$

\begin{tabular}{|c|c|c|c|c|}
\hline & $\begin{array}{l}\text { Item loading } \\
\text { Ist factor }\end{array}$ & $\begin{array}{l}\text { Item loading } \\
\text { 2nd factor }\end{array}$ & $\begin{array}{l}\text { Item loading } \\
\text { 3rd factor }\end{array}$ & $\begin{array}{l}\text { Item loading } \\
\text { 4th factor }\end{array}$ \\
\hline $\begin{array}{l}\text { Since being vaccinated I can go anywhere with } \\
\text { my family or friends }\end{array}$ & 0.645 & 0.206 & 0.082 & 0.441 \\
\hline $\begin{array}{l}\text { Since being vaccinated I no longer have to avoid things } \\
\text { that I like but which caused my allergy }\end{array}$ & 0.858 & 0.071 & 0.213 & 0.074 \\
\hline My vaccine helps me to carry out my daily activities & 0.561 & 0.493 & 0.135 & 0.292 \\
\hline Thanks to the vaccine I can work or study better & 0.688 & 0.404 & 0.120 & 0.298 \\
\hline Since being vaccinated I enjoy outdoor activities more & 0.659 & 0.379 & 0.179 & 0.300 \\
\hline $\begin{array}{l}\text { Since taking the vaccine I do not find myself in compromising } \\
\text { or uncomfortable situations caused by my allergy symptoms }\end{array}$ & 0.813 & 0.123 & 0.200 & 0.117 \\
\hline $\begin{array}{l}\text { The good performance of the vaccine compensates for all the } \\
\text { things I have to do to obtain it (appointments, prescriptions, leave) }\end{array}$ & 0.178 & 0.835 & 0.224 & 0.207 \\
\hline $\begin{array}{l}\text { The good performance of the vaccine compensates for } \\
\text { the financial challenge it causes me }\end{array}$ & 0.199 & 0.784 & 0.272 & 0.270 \\
\hline $\begin{array}{l}\text { The good performance of the vaccine compensates for } \\
\text { any inconveniences it could cause me }\end{array}$ & 0.240 & 0.785 & 0.280 & 0.111 \\
\hline Generally speaking, I am satisfied with my allergy vaccine & 0.305 & 0.463 & 0.635 & 0.322 \\
\hline In general, I would recommend the vaccine treatment & 0.131 & 0.208 & 0.850 & 0.083 \\
\hline My quality of life has improved since receiving the vaccine & 0.343 & 0.368 & 0.557 & 0.447 \\
\hline $\begin{array}{l}\text { Since being vaccinated against my allergy I have } \\
\text { fewer symptoms }\end{array}$ & 0.117 & 0.262 & 0.377 & 0.725 \\
\hline My vaccine works & 0.257 & 0.414 & 0.543 & 0.533 \\
\hline $\begin{array}{l}\text { Thanks to my vaccine, I am less dependent on always } \\
\text { carrying other medication (pills, inhalers) }\end{array}$ & 0.394 & 0.157 & 0.070 & 0.723 \\
\hline My vaccine works faster than I had expected & 0.328 & 0.347 & 0.484 & 0.441 \\
\hline $\mathrm{R}^{2}, \%$ & 55.60 & 9.46 & 5.45 & 4.27 \\
\hline Overall $\mathrm{R}^{2}, \%$ & 74.79 & & & \\
\hline
\end{tabular}

Notes: ${ }^{a}$ The items belonging to each factor/dimension are highlighted in bold gray. Only the five items, highlighted in bold, substantially contributed (load $\geq 0.45$ ) to a second factor. The final allocation of these five items to their respective dimensions was made by means of clinical criteria; the original tool was developed entirely in Spanish; this is not an official version in English, but a translation for informational purposes only.

triumvirate of "satisfaction", "adherence", and "abandonment" of the treatment may go hand in hand. As some recent studies indicate, ${ }^{19,20}$ adherence to allergen-specific immunotherapy treatment would be below desired levels and would be conditioned by aspects related to, eg, inconvenience, ease of administration, cost, lack of efficacy, and adverse reactions, apart from the way the immunotherapy is administered, which suggests that the aspects mentioned feedback to and modulate the allergen-specific immunotherapy-treated allergic patient's satisfaction, and, therefore, will affect the final result regarding the noncompliance or abandonment of the treatment prescribed by the allergologist.

Table 4 Score distributions, floor/ceiling effects, interscale correlations and internal consistency of the 16-retained items $(n=254)$

\begin{tabular}{|c|c|c|c|c|c|}
\hline & GS & PE & $\mathrm{AE}$ & CBB & OS \\
\hline Items (n) & 16 & 4 & 6 & 3 & 3 \\
\hline Mean & 56.8 & 13.9 & 19.9 & 11.2 & 12.2 \\
\hline SD & 14.7 & 3.8 & 6.3 & 3.3 & 2.8 \\
\hline Theoretical range ${ }^{a}$ & $16-80$ & $4-20$ & $6-30$ & $3-15$ & $3-15$ \\
\hline Observed range & $16-79$ & $4-20$ & $6-30$ & $3-15$ & $3-15$ \\
\hline Floor $^{\mathrm{b}}(\%)$ & 0.4 & 2.4 & 4.3 & 2.4 & 0.4 \\
\hline Ceiling $(\%)$ & 0 & 3.9 & 3.1 & 22.8 & 15.7 \\
\hline $\mathrm{CA}$ & 0.94 & 0.79 & 0.89 & 0.89 & 0.83 \\
\hline \multirow[t]{2}{*}{ Interscale correlation range } & $0.822-0.904$ & $0.686-0.900$ & $0.623-0.904$ & $0.632-0.822$ & $0.623-0.86$ \\
\hline & (CBB-AE) & (CBB-GS) & (OS-GS) & $(\mathrm{AE}-\mathrm{GS})$ & $(A E-G S)$ \\
\hline Inter-item correlation range ${ }^{d}$ & $0.537-0.805$ & $0.489-0.698$ & $0.690-0.787$ & $0.765-0.805$ & $0.621-0.743$ \\
\hline
\end{tabular}

Notes: ${ }^{a}$ Overall score ranges from 16 (low satisfaction) to 80 (high satisfaction). Low dimension score indicates low satisfaction while high dimension score indicates high satisfaction; 'Percentage of patients with the worst possible score; 'Percentage of patients with the best possible score; ${ }^{\mathrm{d} C o r r e l a t i o n}$ of corrected item-total.

Abbreviations: GS, Global score; PE, Perceived efficacy; AE, Activities and environment; CBB, Cost-benefit balance; OS, Overall satisfaction; CA, Cronbach's alpha. 
Table 5 Mean (SD) of the 16-retained items ${ }^{a}$, based on symptomatic manifestations of allergy $(n=254)$

\begin{tabular}{|c|c|c|c|c|c|}
\hline & $\begin{array}{l}\text { Global } \\
\text { score }\end{array}$ & $\begin{array}{l}\text { Perceived } \\
\text { efficacy }\end{array}$ & $\begin{array}{l}\text { Activities and } \\
\text { environment }\end{array}$ & $\begin{array}{l}\text { Cost-benefit } \\
\text { balance }\end{array}$ & $\begin{array}{l}\text { General } \\
\text { satisfaction }\end{array}$ \\
\hline \multicolumn{6}{|c|}{ Type of allergic rhinitis } \\
\hline Intermittent & $58.3(14.3)$ & $14.3(3.7)$ & $20.4(6.3)$ & II.7 (3.3) & $12.5(2.7)$ \\
\hline Persistent & $53.5(15.2)$ & I3.I (3.9) & $18.9(6.3)$ & $10.5(3.3)$ & II.5 (2.9) \\
\hline$P$-value ${ }^{\mathrm{b}}$ & 0.042 & 0.009 & 0.055 & 0.002 & 0.027 \\
\hline \multicolumn{6}{|c|}{ Intensity of allergic rhinitis (ARIA) } \\
\hline Mild & $60.1(13.2)$ & $14.9(3.4)$ & $19.9(6.8)$ & II.8 (3.3) & $12.8(2.6)$ \\
\hline Moderate/severe & $55.2(15.2)$ & $13.5(3.9)$ & $20(6.1)$ & II (3.3) & $11.9(2.8)$ \\
\hline$P$-value ${ }^{\mathrm{b}}$ & 0.049 & 0.008 & 0.922 & 0.039 & 0.031 \\
\hline \multicolumn{6}{|c|}{ Presence of bothersome symptoms (ARIA) } \\
\hline No & $59.6(13.3)$ & $14.7(3.5)$ & $20.4(6.7)$ & $11.7(3.2)$ & $12.6(2.6)$ \\
\hline Yes & $54.8(15.3)$ & I3.4 (3.9) & $19.7(6)$ & $10.9(3.3)$ & I I .8 (2.8) \\
\hline$P$-value ${ }^{b}$ & 0.039 & 0.010 & 0.223 & 0.033 & 0.058 \\
\hline \multicolumn{6}{|l|}{ Rhinorrhea } \\
\hline No & $61.6(12.2)$ & $15.3(3.2)$ & $21.5(6.9)$ & $12.8(3)$ & I3.I (2.1) \\
\hline Yes & $55.8(15)$ & $13.6(3.8)$ & $19.6(6.2)$ & $10.9(3.2)$ & $12(2.8)$ \\
\hline$P$-value ${ }^{\mathrm{b}}$ & 0.064 & 0.011 & 0.036 & 0.000 & 0.073 \\
\hline \multicolumn{6}{|c|}{ Intensity of rhinorrhea } \\
\hline Absence of symptoms & $61.6(12.2)$ & $15.3(3.2)$ & $21.5(6.9)$ & $12.8(3)$ & $13.1(2.1)$ \\
\hline Mild symptoms & $57.7(14.2)$ & $13.9(4.1)$ & $19.8(6.3)$ & $11.5(3.3)$ & $12.5(2.7)$ \\
\hline Moderate symptoms & $54.3(14.7)$ & I3.4 (3.4) & $19.3(6)$ & $10.5(3.1)$ & II .4 (2.9) \\
\hline Severe symptoms & $53.9(16.9)$ & $13.4(4)$ & $19.7(6.2)$ & $10.5(3.2)$ & $11.7(3)$ \\
\hline$P$-value ${ }^{c}$ & 0.150 & 0.038 & 0.180 & 0.000 & 0.044 \\
\hline \multicolumn{6}{|l|}{ Sneezing } \\
\hline No & $63.2(11.9)$ & $16.2(2.7)$ & $21(7.3)$ & $12.8(3)$ & I3.7 (I.6) \\
\hline Yes & $55.9(14.8)$ & I3.5 (3.8) & $19.7(6.1)$ & II (3.3) & $12(2.8)$ \\
\hline$P$-value ${ }^{\mathrm{b}}$ & $0.05 I$ & 0.000 & 0.177 & 0.002 & 0.010 \\
\hline \multicolumn{6}{|l|}{ Intensity of sneezing } \\
\hline Absence of symptoms & $63.2(11.9)$ & $16.2(2.7)$ & $21(7.3)$ & $12.8(3)$ & I3.7 (I.6) \\
\hline Mild symptoms & $56.4(14)$ & $13.6(3.7)$ & $19.7(6.4)$ & II .5 (3.3) & I2.I (2.6) \\
\hline Moderate symptoms & $56.2(13.9)$ & I3.5 (3.5) & $20.3(5.6)$ & $10.7(3.1)$ & II.8 (2.8) \\
\hline Severe symptoms & $55(17.3)$ & I $3.5(4.3)$ & 19.1 (6.5) & $10.8(3.3)$ & I2.1 (3.2) \\
\hline$P$-value ${ }^{c}$ & $0.28 \mathrm{I}$ & 0.006 & 0.410 & 0.004 & 0.050 \\
\hline
\end{tabular}

Notes: a Overall score ranges from 16 (low satisfaction) to 80 (high satisfaction). Low dimension score indicates low satisfaction while high dimension score indicates high satisfaction; 'U Mann-Whitney; 'Kruskal-Wallis Test.

There are, at present, instruments to assess patient satisfaction with regard to chronic medication and general medication ${ }^{13-15}$ that identify relevant dimensions (ie, side effects, medication efficacy, or user convenience) with regard to patient satisfaction. Generally speaking, these dimensions could be considered as standard for and common to any patient receiving medication for any illness. However, these scales could be limited when capturing all the patient perceptions associated with the special characteristics of treatment employed with certain illnesses, as would be the case in allergic patients undergoing specific immunotherapy treatment. That is probably why quite a few questionnaires have been developed to measure treatment satisfaction specific for certain illnesses and patient populations. ${ }^{4-12}$ Yet, how can we assess the specific immunotherapy-treated allergic patient satisfaction, and his/her relation to other basic parameters in the clinical management of this population, without having a suitable instrument available? That is why the research team proposed developing what will probably turn out to be the first satisfaction instrument with regard to the specific immunotherapy of allergic adult patients.

The new questionnaire has been originally developed using Spanish-speaking adult patients from Spain (its eventual application to Spanish speakers within a Hispanic culture would be relatively easy after correction for cultural adaptation according to the agreed-upon guidelines for this purpose). ${ }^{34}$ Right from the very beginning, the research team proposed to strictly follow the present standards recommended for any instruments set out in PRO..$^{35}$ In this way, the patient perspective has been included in all the phases described in this article relative to item generation and reduction (with the sole exception of the six items eliminated on the basis of clinical qualitative criteria, mainly because the statistical and quantitative arguments did not allow the 
establishment of relevant differences between them). We believe that the patient perspective has contributed to the validity of the questionnaire's content, as well as concentrating the content of the measure on those aspects relevant to the patient at the time of assessing his/her satisfaction with allergen-specific immunotherapy.

Also, a strength of our study includes the use of a range of sources to generate items for inclusion in the initial item pool, and the explicit incorporation of the views of the potential users of the questionnaire (allergologists) right from the start of the development process. The use of a clinimetric analysis also ensured that the most frequently occurring and/or most relevant items were included in the questionnaire, although there is no consensus with respect to which of the item reduction method processes is the most suitable. ${ }^{36}$ The final version of the instrument contains 16 items, which clinicians participating in the development process felt was a suitable number for use in clinical practice. This measure has been developed with the belief of converting it into a real instrument for the physicians who normally manage allergic patients with allergen-specific immunotherapy. For this reason, two other aspects considered relevant by clinicians, and that were borne in mind during the development of the measure, were that the questionnaire should be easy to use and score.

The results of the preliminary analysis on the psychometric properties of the new measure provide satisfactory evidence with respect to the feasibility, reliability, and validity of the questionnaire, although their testing was not the main goal of these phases of the project, neither was the study design adapted to this. On the one hand, only a low percentage of patients $(<5 \%)$ obtained the worst or the best possible overall and dimension scores, which suggests that the questionnaire satisfactorily covers the satisfaction level of the target population under study. It can also be taken as an indication of whether a measure will, at least theoretically, be capable of reflecting changes for better or worse, within acceptable limits in all dimensions, with fewer than $15 \%$ of patients having either the maximum or the minimum score in any of the dimensions or the overall score. ${ }^{37}$ This is true except for the cost-benefit balance dimension in which $23 \%$ of the sample patients got the highest (best) possible score. This is an aspect which should be re-assessed in the validation study that is being developed, and which would confirm effectively whether the content and cover of this dimension is insufficient to capture the existing satisfaction of a part of the study target.

On the other hand, the Cronbach's alpha coefficients obtained were satisfactory. The Cronbach's alpha values for all the dimensions and for the overall score exceeded the suggested minimum of 0.70 for use at group level. ${ }^{26,27}$ The overall score exceeded 0.90 , which has been suggested as being the threshold for a questionnaire of this type when used at the individual level. ${ }^{37}$ This is particularly important, given that the aim of the study was to produce a questionnaire that could be used to assess and monitor individual patients in clinical practice. However, bearing in mind that the values being reported were obtained within the context of the item reduction study, ie, from patients who answered 70 items twice, these values could change when patients complete the final version of the questionnaire and are required to respond, only once, to each of the 16 items.

The principal component analysis done on the 16 retained items yielded a good factorial solution, identifying four factors, the items for which were reasonably well grouped with regard to their content and the conceptual frame corresponding to the assessment of patient satisfaction with treatment. This result supports the evidence that the new questionnaire has good structural validity and reflects the multidimensionality of the concept, very much in agreement with those proposed in the most significant revisions. ${ }^{9,38-41}$ In this sense, the new instrument includes items about treatment-related effectiveness and symptom relief, functioning, discomfort, and side effects, cost and accessibility to treatment, and general satisfaction. All the aforementioned are topics or domains habitually related to patient satisfaction with treatment, ${ }^{25-29}$ together with other aspects initially included in the initial item pool, and which were eliminated at some time during the item reduction process (eg, disease-related information or regimen characteristics).

Moreover, the preliminary validity analysis of known groups showed that the new tool's scores behave coherently within the expectable, with regard to the compared and defined groups.

A limitation of our study could be the eventual limited number of focus groups used for the item-generation phase. However, the concept to be measured (satisfaction with allergen-specific immunotherapy among allergic adult patients) seems to be a reasonably limited concept, and presumably it has been sufficiently well represented for the purpose of the study because the saturation of issues raised in different focus groups was high. On the other hand, the sample size available for exploring the preliminary validity of the questionnaire probably does not have sufficient statistical power to be able to identify as statistically significant some differences found in this analysis, because the main aim of the field work was to reduce items. Lastly, an exhaustive 
assessment of psychometric properties should be performed in the future before reliably reaching conclusions about the usefulness of the new measure. A formal validation process is currently in progress.

\section{Disclosure}

The authors report no conflicts of interest in this work.

\section{References}

1. Weaver M, Patrick DL, Markson LE, et al. Issues in the measurement of satisfaction with treatment. Am J Manag Care. 1997;3(4):579-594.

2. Revicki D. Patient assessment of treatment satisfaction: Methods and practical issues. Gut. 2004;53 Suppl IV:40-44.

3. Shikiar R, Rentz AM. Satisfaction with medication: An overview of conceptual, methodologic, and regulatory issues. Value Health. 2004; 7(2):204-215.

4. Donatti C, Wild D, Horblyuk R, et al. Psychometric evaluation of the Satisfaction with Oral Anti-Diabetic Agent Scale (SOADAS). Diabetes Res Clin Pract. 2008;80(1):108-113.

5. Atkinson MJ, Stewart WC, Fain JM, et al. A new measure of patient satisfaction with ocular hypotensive medications: The Treatment Satisfaction Survey for Intraocular Pressure (TSS-IOP). Health Qual Life Outcomes. 2003;1:67.

6. Ruiz MA, Heras F, Alomar A, et al; GEIDAC Group. Development and validation of a questionnaire on "Satisfaction with dermatological treatment of hand eczema"(DermaSat). Health Qual Life Outcomes. 2010;8:127.

7. Deal LS, Williams VS, DiBenedetti DB, Fehnel SE. Development and psychometric evaluation of the Endometriosis Treatment Satisfaction Questionnaire. Qual Life Res. 2010;19(6):899-905.

8. Brose LS, Bradley C. Psychometric development of the retinopathy treatment satisfaction questionnaire (RetTSQ). Psychol Health Med. 2009;14(6):740-754.

9. Baró E, Casado A, García-Cases C, et al. Assessing satisfaction with pain medication in primary care patients: Development and psychometric validation of a new measure. Clin Ther. 2004;26(7): 1124-1136.

10. Evans CJ, Trudeau E, Mertzanis P, et al. Development and validation of the Pain Treatment Satisfaction Scale (PTSS): A patient satisfaction questionnaire for use in patients with chronic or acute pain. Pain. 2004;112(3):254-266.

11. Hill CD, Fehnel SE, Bobula JD, Yu H, McLeod LD. Development and preliminary validation of the Menopause Symptoms Treatment Satisfaction Questionnaire (MS-TSQ). Menopause. 2007;14(6) 1047-1055.

12. Beyer AP, Szeinbach SL, Seoane-Vazquez EC, et al. Assessing the reliability and validity of a newly developed insomnia treatment satisfaction questionnaire (ITSAT-Q). Sleep Med. 2010;11(8):766-771.

13. Atkinson MJ, Kumar R, Cappelleri JC, Hass SL. Hierarchical construct validity of the treatment satisfaction questionnaire for medication (TSQM version II) among outpatient pharmacy consumers. Value Health. 2005;8 Suppl 1:S9-S24.

14. Atkinson MJ, Sinha A, Hass SL, et al. Validation of a general measure of treatment satisfaction, the Treatment Satisfaction Questionnaire for Medication (TSQM), using a national panel study of chronic disease. Health Qual Life Outcomes. 2004;2:12.

15. Ruiz MA, Pardo A, Rejas J, Soto J, Villasante F, Aranguren JL. Development and validation of the Treatment Satisfaction with Medicines Questionnaire (SATMED-Q). Value Health. 2008;11(5):913-926.

16. Bousquet J, Khaltaev N, Cruz AA, et al. Allergic Rhinitis and its Impact on Asthma (ARIA) 2008 update (in collaboration with the World Health Organization, GALEN and AllerGen). Allergy. 2008;63 Suppl 86:8-160.
17. Bousquet J, Lockey R, Malling HJ, et al. Allergen immunotherapy: Therapeutic vaccines for allergic diseases. World Health Organization. American Academy of Allergy, Asthma and Immunology. Ann Allergy Asthma Immunol. 1998;81(5 Pt 1):401-405.

18. Canonica GW, Bousquet J, Casale T, et al. Sub-lingual immunotherapy: World Allergy Organization Position Paper. Allergy. 2009;64 Suppl 91: $1-59$.

19. Senna G, Ridolo E, Calderon M, et al. Evidence of adherence to allergen-specific immunotherapy. Curr Opin Allergy Clin Immunol. 2009;9(6):544-548.

20. Incorvaia C, Mauro M, Ridolo E, et al. Patient's compliance with allergen immunotherapy. Patient Prefer Adherence. 2008;2:247-251.

21. Kyngas H. A theoretical model of compliance in young diabetics. J Clin Nurs. 1999;8(1):73-80.

22. Viciana P, Rubio R, Ribera E, et al. Longitudinal study on adherence, treatment satisfaction, and effectiveness of once-daily versus twice-daily antirretroviral therapy in a Spanish cohort of HIV-infected patients (CUVA study). Enferm Infecc Microbiol Clin. 2008;26(3):127-134. Spanish.

23. Kumar RN, Kirking DM, Hass SL, et al. The association of consumer expectations, experiences and satisfaction with newly prescribed medications. Qual Life Res. 2007;16(7):1127-1136.

24. Kitzinger J. Qualitative research. Introducing focus groups. BMJ. 1995;311(7000):299-302.

25. Streiner DL, Norman GR. Health Measurement Scales: A Practical Guide to their Development and Use. 2nd ed. Oxford, UK: Oxford University Press; 1995.

26. Lohr KN, Aaronson NK, Alonso J, et al. Evaluating quality-of-life and health status instruments: Development of scientific review criteria. Clin Ther. 1996;18(5):979-992.

27. Nunnally J, Bernstein IH. Psychometric Theory. 3rd ed. New York, NY: McGraw-Hill; 1994

28. Perpiñá Tordera M, Viejo JL, Sanchis J, et al. Assessment of patient satisfaction and preferences with inhalers in asthma with the FSI-10 Questionnaire. Arch Bronconeumol. 2008;44(7):346-352. Spanish.

29. De Vries U, Mühlig S, Waldmann HC, et al. Patient satisfaction with different asthma-training variants. Patient Educ Couns. 2008;70(2): 266-275.

30. Hutter HP, Moshammer H, Wallner P. Determinants of patient satisfaction with services of the Vienna environmental medicine counseling center. Gesundheitswesen. 2001;63(4):238-241. German.

31. Gallefoss F, Bakke PS. Patient satisfaction with healthcare in asthmatics and patients with COPD before and after patient education. Respir Med. 2000;94(11):1057-1064.

32. Weiss KB, Paramore LC, Liljas B, et al. Patient satisfaction with budesonide Turbuhaler versus triamcinolone acetonide administered via pressurized metered-dose inhaler in a managed care setting. J Asthma. 2005;42(9):769-776.

33. Didier A, Vervloet D, Fontaine J, et al. Development and validation of a questionnaire dedicated to the management of adults patients treated with sublingual immunotherapy for allergic rhinitis. Presented at the 25th Congress of the European Academy of Allergology and Clinical Immunology, June 10-14, 2006, Vienna, Austria.

34. Wild D, Grove A, Martin M, et al. ISPOR Task Force for Translation and Cultural Adaptation. Principles of good practice for the translation and cultural adaptation process for patient-reported outcomes (PRO) measures: Report of the ISPOR Task Force for Translation and Cultural Adaptation. Value Health. 2005;8:94-104.

35. US Department of Health and Human Services FDA Center for Drug Evaluation and Research; US Department of Health and Human Services FDA Center for Biologics Evaluation and Research; US Department of Health and Human Services FDA Center for Devices and Radiological Health. Guidance for industry: patient-reported outcome measures: use in medical product development to support labeling claims: Draft guidance. Health Qual Life Outcomes. 2006;4:79. 
36. Juniper EF, Guyatt GH, Streiner DL, et al. Clinical impact versus factor analysis for quality of life questionnaire construction. J Clin Epidemiol. 1997;50(3):233-238.

37. McHorney CA, Tarlov AR. Individual-patient monitoring in clinical practice: Are available health status surveys adequate? Qual Life Res. 1995;4(4):293-307.

38. Abetz L, Coombs JH, Keininger DL, et al. Development of the cancer therapy satisfaction questionnaire: Item generation and content validity testing. Value Health. 2005;8 Suppl 1:S41-S53.

39. Ruiz MA, Pardo A, Martinez de la Casa JM, et al. Development of a specific questionnaire measuring patient satisfaction with glaucoma treatment: Glausat. Ophthalmic Epidemiol. 2010;17(3):131-143.
40. Delgado Martín JA, Blázquez Izquierdo J, Silmi Moyano A, et al. Determining factors in patient satisfaction with erectile dysfunction treatment. Actas Urol Esp. 2008;32(10):995-1003. Spanish.

41. Olden K, DeGarmo RG, Jhingran P, et al. Patient satisfaction with alosetron for the treatment of women with diarrhea-predominant irritable bowel syndrome. Am J Gastroenterol. 2002;97(12):3139-3146.

42. Valero A, Ferrer M, Sastre J, et al. A new criterion by which to discriminate between patients with moderate allergic rhinitis and patients with severe allergic rhinitis based on the Allergic Rhinitis and its Impact on Asthma severity items. J Allergy Clin Immunol. 2007;120(2): 359-365.

\section{Publish your work in this journal}

Patient Preference and Adherence is an international, peer-reviewed, open access journal focusing on the growing importance of patient preference and adherence throughout the therapeutic continuum. Patient satisfaction, acceptability, quality of life, compliance, persistence and their role in developing new therapeutic modalities and compounds to optimize clinical outcomes for existing disease states are major areas of interest. This journal has been accepted for indexing on PubMed Central. The manuscript management system is completely online and includes a very quick and fair peer-review system. Visit http://www.dovepress.com/ testimonials.php to read real quotes from published authors. 